\title{
PARTICIPATORY APPROACH FOR THE ENHANCEMENT OF ARCHITECTURAL ARCHIVES FUNDS: THE EXPERIENCE AT MUSEO DELLA RAPPRESENTAZIONE IN CATANIA
}

\author{
C. Santagati ${ }^{1, *}$, G. D'Agostino ${ }^{1}$, R. Garozzo ${ }^{1}$, F. M. La Russa ${ }^{1}$, M. Galizia ${ }^{1}$ \\ ${ }^{1}$ Department of Civil Engineering and Architecture, University of Catania, Italy - \\ (csanta, mgalizia)@dau.unict.it (graziana.dagostino, raissa.garozzo)@unict.it, (federico.larussa)@phd.unict.it
}

Commission V, WG V/7

KEY WORDS: digital cultural experience, architectural heritage, digital survey, museum collections, participation

\begin{abstract}
:
This paper describes the results of a participatory approach experienced during the training of university and high school students at the MuRa (Museo della Rappresentazione). Mura is a university museum belonging to the Department of Civil Engineering and Architecture at University of Catania. It houses and exhibits the collections of architectural projects of Francesco Fichera and a series of chalcographies including the collection of the renown engraver Giovan Battista Piranesi. The training program has been addressed at the documentation, visualization and communication of the architectures realized by Francesco Fichera and other Sicilian architects in the city centre of Catania in the first half of $\mathrm{XX}^{\text {th }}$ century, whose projects are hosted by the museum. The methodology adopted has included the experimentation of participatory strategies aimed at the communication and the narration of the architectures built in the early twentieth century in Catania. After a preliminary training phase on digital tools for 3D documentation and enhancement of architectural heritage, the students were invited to participate with their ideas and creative expressions in the dissemination actions of the identified case studies.
\end{abstract}

\section{INTRODUCTION}

University museums and collections play fundamental roles in graduate and post-graduate courses as well as in high school training programs. As stated in the mission of the International Committee for University Museums and Collections of the International Council of Museums (UMAC, 2017), they are places where research, education and museum practices are brought together with the common goal to preserve, enhance and communicate the collections to the territory, thus becoming a centre of mediation between science and the wide public.

The presence of equipped laboratories allows for activities that develop practical skills and competences which are not only in the realm of museum professionals but also related to other fields.

The integration of research/didactic activities and the use of current IT tools could bring towards novel approaches in terms of digital innovation for Cultural Heritage enhancement and communication as well as new ways of curation and visitors engagement. This way the students activity takes place in a vibrant and fruitful environment where novel ideas can arise such as the development of communicative participatory forms that can embrace the cultural needs of a diversified target of users (Galizia et al., 2019).

In this context, this paper describes the results of a participatory approach experienced for the enhancement and communication of the museum collections hosted at the MuRa (Museo della Rappresentazione, Museum of Representation) at University of Catania. The museum is part of the university of Catania museums network (SiMuA). The museum heritage consists of different drawn and printed collections, such as the projects by architect Francesco Fichera and the drawings by Giovan Battista Piranesi as well as other minor engravers.

Design drawings are mainly technical drawings (plans, elevations, cross-sections), thus very hard to understand by non- professionals. Therefore, this heritage can become an opportunity both for academics and for students to experiment new forms of documenting, understanding and communicating Architecture. Degree thesis, $\mathrm{PhD}$ researches, internships/ educational programs and degree courses could become the field work where to develop cultural contents, illustrate practices and develop new skills.

The experimentation was addressed at the enhancement of Francesco Fichera works whose design projects are exhibited at the museum and constitute iconic buildings in the urban landscape of Catania.

The participatory approach adopted both with university and high school students emphasizes the centrality of the design drawings and digital survey for understanding of Architectural heritage. After a preliminary training phase on digital tools for 3D documentation and enhancement of architectural heritage, they were invited to participate with their ideas and creative expressions in the documentation, communication and dissemination actions of the identified case studies. This way they took awareness of some of the most important built heritage in the city of Catania putting in practice Faro Convention's principles on wider understanding of heritage and its relationship with communities and society.

\subsection{The mission of the Museo della Rappresentazione in Catania}

The Museo della Rappresentazione is part of the network of university of Catania museums and is managed by the Department of Civil Engineering and Architecture. It was established in 1997 within the Catania-Lecce Project which was aimed at the development of actions for preserving and enhancing the rich heritage of the two universities. The project included the restoration of Villa Zingali Tetto with the aim of

* Corresponding author 
making it the seat of the museum. This historical building has been designed by the architect Paolo Lanzerotti and built in 1930 (Fig. 1). According to the Catania-Lecce project the museum would have hosted, preserved and exhibited the project funds and the collections before conserved at the Department of Architecture and Urban Planning (La Russa, 2019). Among the valuable collections conserved at MuRa we can cite the projects of architect Francesco Fichera and the prints by the engraver Giovan Battista Piranesi (Fig. 2).
The museum activities restarted after six years of closure in 2016 with a new director and scientific committee that adopted a novel vision for the museum as a place where not only to preserve but also to experiment innovative ways for coproduction and sharing cultural heritage in terms of engagement, lifelong learning, edutainment, lowering sociocultural barriers.
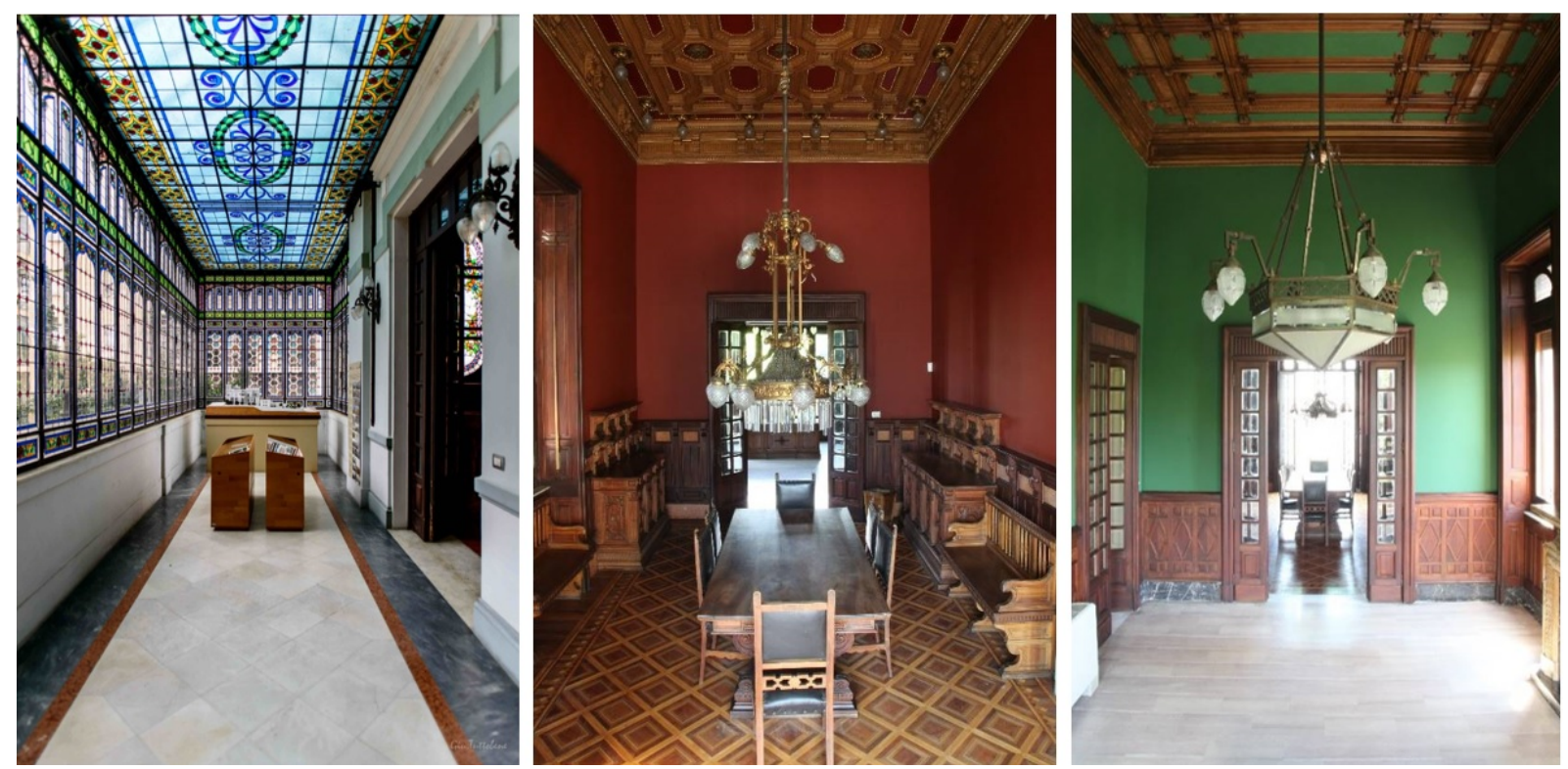

Figure 1. View of the interior of MuRa (from left to right): winter garden, dining room, office

Francesco Fichera (1881 - 1950) was an architect and professor at University of Catania. He was one of the most important designer in Sicily in the first half of $\mathrm{XX}^{\text {th }}$ century. In 1976 the heir donated his projects to University. The archive consist of 1600 drawings as well as heliographic copies. As for Giovan Battista Piranesi $(1720$ - 1778), the collection embeds 1048 tables of engravings and 187 text tables. These were reprinted by the Royal Calcography of Rome from 1933 to 1960 and sent to Francesco Fichera, that time director of the Institute of Ornate and Architecture at the University of Catania (Santagati, 2017).
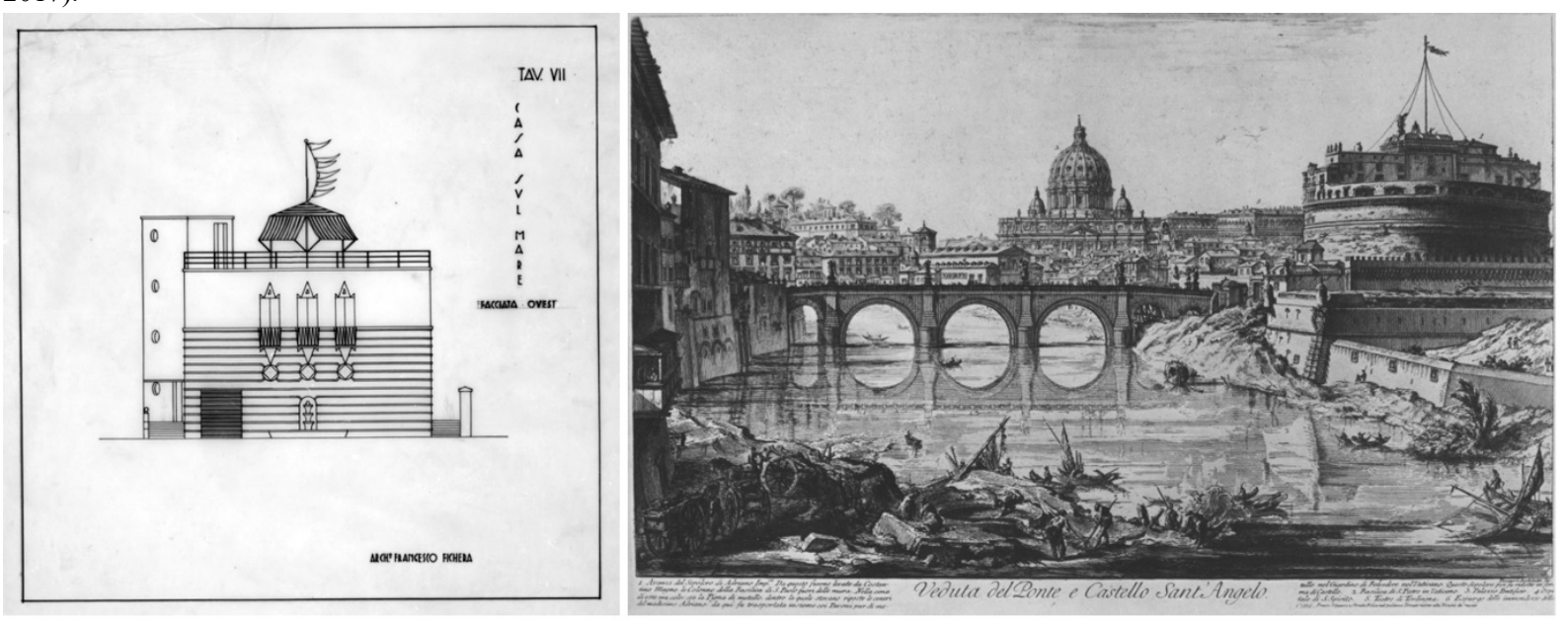

Figure 2. Museum collections (from left to right): elevation view of the project La casa sul Mare (Francesco Fichera,
The main topics of the new management were (and still are) protecting and making available to the scientific community and to the territory the results of the Department research, education and dissemination activities.

At MuRA the two main missions of university - educational and research - are closely intertwined with the third one, that is the relation with the society, in a unique combination of innovative approaches to didactic, research and dissemination. This led to the setting up of two laboratories that are increasingly becoming the bridge between science, students and citizens.

\footnotetext{
1933); View of Castel Sant'Angelo (Giovan Battista Piranesi, 1754).
} 
In this framework, a pivotal role is played by the application of digital technologies in cultural heritage field both from an educational and a research point of view allowing also for new participative approaches aimed at the contamination between expertise and perspectives. The museum becomes a place where new professionals are trained and the activities are opened to the territory (schools, associations).

In this context, the museum is responsive to feedbacks from the territory, both in terms of communication strategies and cocreation of content, and has promoted educational projects with high schools through innovative teaching system which aim to enrich training and orient study paths towards new skills that respond to the demands of the contemporary digital revolution (Luigini and Panciroli, 2018).

\section{METHODOLOGY}

The experimentation carried out was driven by the interaction between the three missions of the MuRa -Didactics, Research and Third Mission- through a participatory approach. In this framework of activities, which pursue the common objective of knowledge, communication and fruition of historical-archival heritage, the methodology adopted envisages the experimentation of bottom up strategies aimed at the active and collaborative engagement of high school and university students in the co-creation of digital contents.

Specific training workflows have been developed both for architecture and engineering students and for high school students that worked on the architecture designed and built at the beginning of the 20th century in Catania (Galizia, 2002; Guerrera, 2017) by the major exponents of architectural culture such as Francesco Fichera, Carmelo Aloisi (1894-1970) and Paolo Lanzerotti (1875-1949).

The first training step foresaw, for both student groups, the critical analysis and reading of the project drawings preserved in the archive, to understand the poetics of the designers and to investigate the spatiality and geometry of the architectural projects.

The next phase provided a different methodological approach for the two cases, closely linked to the knowledge and the skills of the trainees involved as well as to the aims of the educational projects.

The methodological approach adopted with high school students considered the age range of the students involved (16-17 years old), their technical skills, their experience in the architectural field, the timing and purpose of the project.

Drawing inspiration from the attitude of young generations to social networks and according to a vision of open culture, students were invited to create 3D digital models of Fichera's architectures to be spread on line. This way trainees had the opportunity to become promoters of the local historicalarchitectural heritage by using digital tools in terms of 3D surveying, visualization and communication.

The students started photogrammetric survey campaigns, adopting SfM (structure from motion) technology, and used their smartphones or professional cameras to survey the chosen architectures. The images were processed to obtain 3D models easily explorable in their geometric, dimensional, formal, material, chromatic contents. Furthermore the models have been optimized and uploaded on the web platform Sketchfab so that to be explored online. Therefore, these products are also a good asset to better understand the design drawings exhibited.

Otherwise, the experience conducted with university students has taken into account the scientific skills to be transmitted to future engineers by means of Architectural Drawing course contents: the knowledge of the geometry underlying the form of architectural elements; descriptive geometry; direct, instrumental and photogrammetric surveying.

First of all, the students became familiar with architecture by drawing sketches from the real world and eidotypes (plans, elevations, details). Secondly, they proceeded with direct survey integrated by instrumental (Terrestrial Laser Scanner - TLS) and photogrammetric (SfM techniques) surveys.

The interpretation of acquired data has produced an accurate two-dimensional graphic restitution and has allowed for the digital $3 \mathrm{D}$ reconstruction of the most significant architectural elements.

The last phase concerned the exhibition and therefore the relation between the curator, the work and the visitor, through the use of new paradigms of interaction and fruition. In this perspective, the students were the protagonists of a participatory process, playing the dual role of visitors and curators of the design content produced, through solutions that communicate the path of knowledge of the examined architectures.

Francesco Fichera's architecture is illustrated in a clear and engaging way by means of exhibition panels. This experience has given the opportunity of an interactive dialogue with the museum's visitors in order to develop strategies for an effective communication of the museum's cultural contents.

The exhibition open to the city on the occasion of the researchers night 2019, gave rise to a dialogue between students and MuRa visitors, gathering feedback on the effectiveness and engagement of new possible exhibition archetypes.

The participatory process has thrilled not only the young students, who have taken an active part in the elaboration of the museum content, but also the groups of museum visitors who, with their feedback, have contributed to the improvement of the exhibition design in terms of understanding, transmission, involvement and attachment to the architectural and archival heritage, which is the memory of the territory.

\section{TRAINING DIGITAL SKILLS TO YOUNG GENERATIONS: CRITICALITIES AND OPPORTUNITIES}

Being able to train, motivate and guide students from different educational backgrounds, such as high school and university, has always been a great challenge for a teacher or an educational institution. The awareness and training of future professionals is one of the main themes of the survey developed by UMAC in 2019. Current digital revolution in the field of documentation and valorisation of the existing cultural heritage requires specific skills.

The process of knowledge of an artifact, whether it is an architecture, an archaeological site, a landscape or a work of art, starts from the understanding of the value of the asset itself. Especially in the architectural and archaeological field, the survey phase accomplishes the fundamental task of acquisition and rigorous documentation of dimensional, geometric, formal and material data. Digital survey - TLS or SfM - provides a 3D model useful to document the object in its complexity and spatiality. Therefore, it is fundamental to provide students both technical and theoretical awareness of the reliability of the instruments and digital models obtained.

Beginners in digital surveying methodology often assume that through the correct use of a tool they would acquire all the knowledge about an asset, without too much practical and/or intellectual efforts.

This occurs because, at first impact, the operator, professional or not, is fascinated by the speed and detail of the point clouds, and does not consider them as the first step in the process of knowledge and documentation but as the final act. 
However, digital technology should always be intended as a tool at the service of rigorous studies and research, which require cultural skills to critically interpret and manage the amount of data acquired, so as to make them useful and comprehensible (Migliari, 2004). It is right, therefore, to examine critically how to train future professionals on digital skills related to the themes of documentation and enhancement of cultural heritage. The data acquisition and visualization speed, together with the possibility of the semi-automatic extraction of sections, orthophotos or 3D views, must be commensurate with the rigorousness of the result. Certainly the survey phase is now easier thanks to the automatic metric and colorimetric information acquisition. Consider, for instance, the amount of data that a TLS acquires in a very short time or the easiness of making a photo dataset, by owning a camera.

It is essential to be aware of the role that skills and fieldwork experience play in the definition of a proper survey project. The redundancy of the acquired data, if on the one hand allows the extraction of any information at a later time, on the other hand can make difficult the management of the data in the postprocessing phase, both at computational and interpretative level. The rules for carrying out a correct photographic dataset and post-processing instructions provided by automatic digital photogrammetry software are useful to generate a textured, complete and scaled three-dimensional model, but its level of accuracy and the final metric quality must be verified.

The reliability of the used instrumentation is important. On the market there are different Terrestrial Laser Scanners available depending on the object to be surveyed and the site conditions. For the correct choice of a TLS it is necessary to deepen the technical characteristics in terms of instrument range and data accuracy. For a survey using SfM methodology can be used a common camera, but the use of a calibrated or uncalibrated camera greatly affects the data quality (Bitelli et al, 2020; Santana et al., 2017).

The purpose of a 3D acquisition determines the choice of the survey technique to adopt and the type of three-dimensional model or two-dimensional restitution that will be obtained.

The aim of the survey can be focused on the documentation, the preservation and enhancement of architecture and cultural heritage, the management of digital archives and the creation of virtual reconstructions through VR, AR and MR technologies, or addressed to the management of complex knowledge systems, such as H-BIM methodology application. The choice of the survey methodology to be used, instead, is strongly dependent on the size and shape of the studied object, on the metric accuracy required and on the survey modalities. Objective surveying and subjective interpretation are two fundamental aspects on which the process of conveying information and acquiring digital skills related to surveying, visualizing and communicating cultural heritage is based.

From the above we can see the importance of the professional figure in the interpretation and understanding of the architectural forms of the investigated artefact.(Gaiani, 2018).

\section{HIGH SCHOOL STUDENTS TRAINING EXPERIENCE: FROM SFM TECHNIQUES TO THE HACKABLE MUSEUM}

"School-work alternance" (CEDEFOP, 2018) is a program for combined school-based and work-based traineeships, promoted by the Italian Government since 2015, that helps to consolidate the knowledge acquired at school through practical experience. In addition, it supports students in discovering their attitudes in a chosen field, enriches their education and orients their study path in line with their curriculum and skills. In 2019, "schoolwork alternance" has been updated and replaced by Transversal
Competence and Orientation Paths project and it still is obligatory for all students of the last three years of high schools. This program allows a closer contact between high-schools and museums since these latter are places where culture and education meet multidisciplinary, problem-solving and management skills. Museums not only as cultural hubs but also places for the training of future professionals. In this work, it will be exposed the "school-work alternance" experience between MuRa and the high-school of fine arts "M. Lazzaro" in Catania within the \#3DDigitalInvasions project.

\#3DDigitalInvasions were inspired by \#DigitalInvasions initiative, an Italian bottom-up project started in 2013. This initiative consists in free event made by local communities that want to divulgate their cultural heritage through pictures shared in social media with well-defined hashtags.

\#3DDigitalInvasions is the evolution of this idea moving from 2D products (images) to 3D products (models) using mostly SFM techniques. This new initiative took place in Sicily since 2015 and engaged students from University of Catania and Palermo (Bonacini et al., 2015).

The group of students involved, 15 individuals, was already skilled in photographic and video-editing techniques for artistic purposes. Until then, they never experienced to use images to reconstruct $3 \mathrm{D}$ models from reality. The entire activity lasted 40 hours of which:

- 15 hours of lectures regarding university orientation, museums and exhibitions, the role of architectural project archives for citizens engagement and identity, architectural survey and SFM techniques;

- 5 hours of survey activities on site;

- 20 hours of processing dataset, editing media contents and web sharing of results.

The starting point of this experience was developing new knowledge and skills through a brief and significant lecture about architectural survey and SFM techniques. This lesson has been made up focusing especially in communication impact of visualizing a 3D textured model. For this reason, the architectural survey has been explained as the "methodology" more than the "goal" demonstrating, in this way, how concepts deeply linked with architecture (like survey and representation) can be useful in other fields. The lesson included also hands-on applications of SFM techniques on some furniture items of the museum engaging directly the students in the process and letting them using their own smartphones as capture cameras. In this way, adopting the same methodology with professionals instruments and solutions they would have the possibility to obtain 3D models with greater accuracy (Santagati et al, 2017).

Once this first phase of teaching has been completed, the case studies were described and assigned to different groups that were helped by tutors (engineering-architecture degree course students). The choice of the case-studies has considered the possibility to have different scenarios of architectural surveying of buildings documented in the museum's archives. This would encourage the students to share their own experience in a peerto-peer education perspective: teamwork is not only about reaching a target together but also improving ourselves through exchange and partnership.

They were selected three buildings realized in the historic centre of Catania, the high-school building Istituto Tecnico Commerciale De Felice, the post office building Palazzo delle Poste, and the residential buildings Casa Lazzara and Casa Mammana (this last one realized by architect Carmelo Aloisi).

The Istituto Tecnico Commerciale De Felice (designed by Fichera in 1926) consists of two floors with a planimetric composition that fits with a trapezoidal shape. The wide square in front of it and the planar facades allowed to easily take 
picture and to process a significant portion of his exteriors. Managing large dataset was the main challenge for the students that get involved into it.

The Palazzo delle Poste (designed by Fichera in 1919) consists of three levels and is characterized by facades in lava and lime stone. These ones define convex spans marked by pilasters of giant order. The surveys have been conducted on an uncommon vault at the main entrance, a sculpture in the side entrance and one lava stone sculpture located on the main façade on the exterior. This public building is currently operative and very crowded during all day hours. These conditions showed to highschool students that is fundamental planning a SFM survey before get in to the site and how to manage unpredictable circumstances.

The residential buildings Casa Lazzara (designed by Fichera in 1919) and Casa Mammana (designed by Aloisi in 1920) are adjacent constructions located in a corner of a city block. Both of them are divided in two levels and are among first representatives of 'modern style' (Casa Lazzara) and 'decò style' (Casa Mammana) developed in catanese architecture at the beginning of $\mathrm{XX}^{\text {th }}$ century. Due to the particular spatial configuration of the facades and the size of the road around, the focus of this case study were the optimization of focal length and the overlapping amount of photos needed to cover the corner.
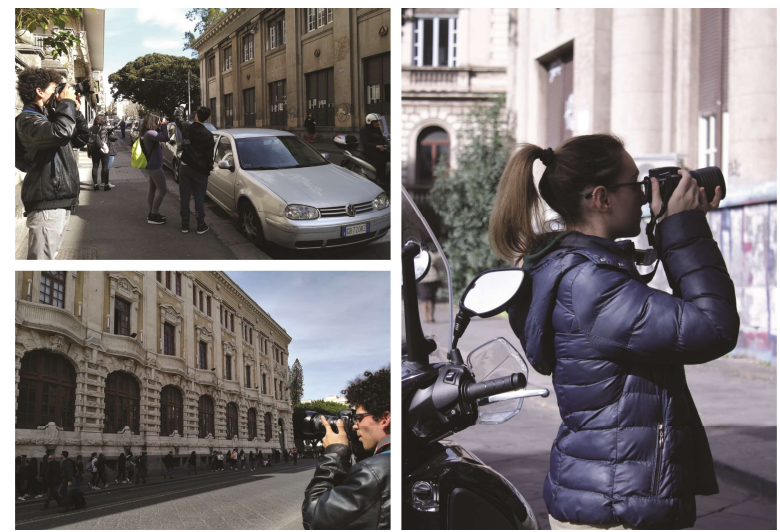

Figure 3. High school students during SFM survey activities.

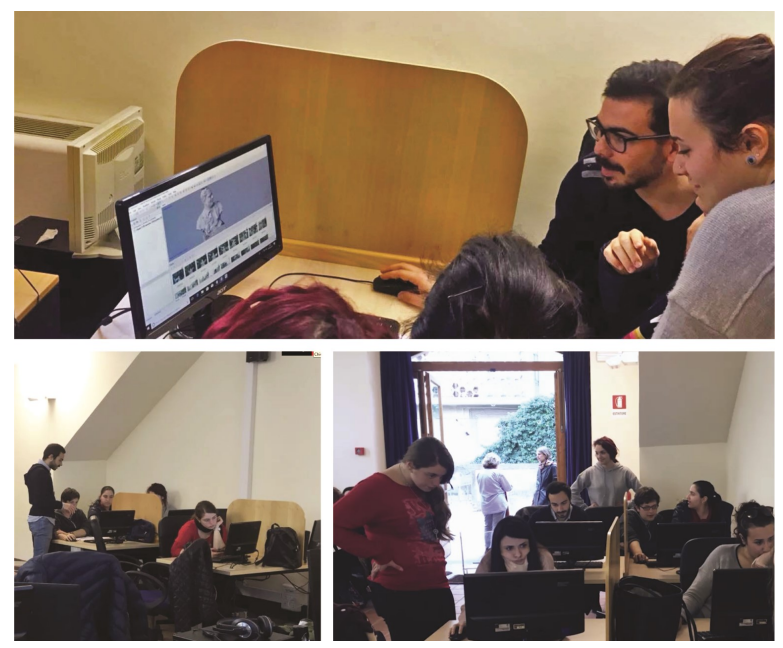

Figure 4. Processing datasets with tutors in MuRa's laboratories.

The cameras used in sites were reflex type ranging from entrylevel to professional classes (Fig. 3). All 3D models have been processed using Agisoft Photoscan 1.4.1 from sparse cloud to textured mesh. Then, it has been used Recap Photo to refine and decimate the textured meshes obtained. The average amount of photos for each dataset is around 50 images (Fig. 4).

With regard to the web dissemination of the models produced, various solutions were examined, including the use of Sketchfab, Europeana, and 3DHop. Sketchfab was chosen because it is the most widespread and it is accessible without any particular background knowledge. This platform has been used for years by various museums (British Museum, Musée d'Archeologie Nationale and others), for the ease of embed 3D content on websites and platforms and for the possibility of direct access to social networks or the connection to guided tour apps (GuidiGO). The high school students created a collection inside the MuRa's web gallery on Sketchfab and uploaded their processed models and giving them a short description (Fig. 5) (Santagati et al., 2018).

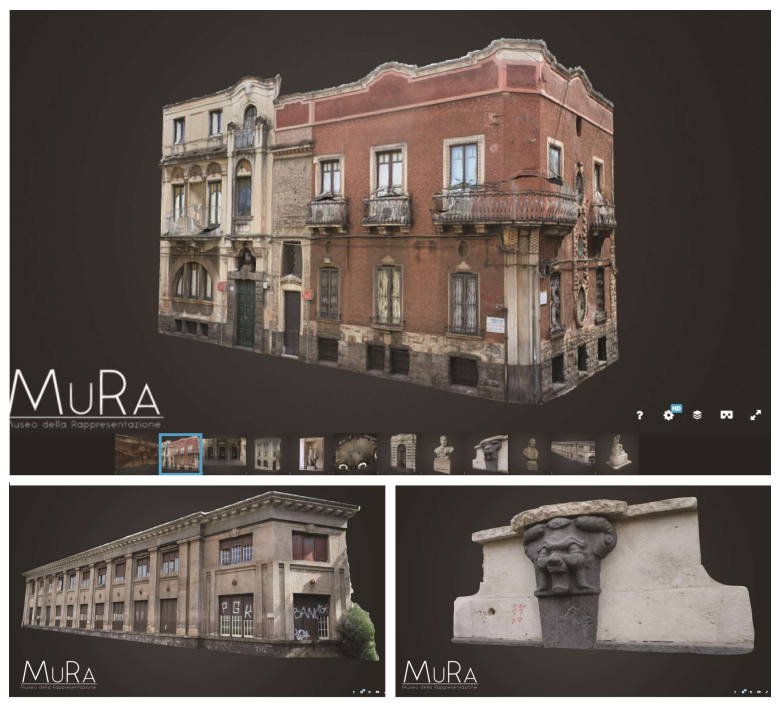

Figure 5. Collection of 3D textured models optimized for web visualization and uploaded inside MuRa's web gallery on Sketchfab.

During all phases of this activity, a group of students was in charge of filming the whole activity trying to capture as many feedbacks as possible. This documenting activity was very important for a final meeting where this video has been discussed and then shared through social media with the purpose of divulgate the cultural heritage subject of this experience and, at the same time, the activity of the two institutions involved. All the feedbacks were used to better plan future activities and replicate this experience.

\section{A TEST CASE FOR ARCHITECTURE- ENGINEERING STUDENTS: THE EXPERIENCE OF SHARPER NIGHT EXHIBITION}

The study of architectural shape plays a key role in the education of future engineers and architects. For this reason, the activities conducted within the Disegno dell'Architettura (Drawing of Architecture) course had, as a goal, the creation of a cognitive background based on the analysis, survey, and discretization of architecture. The first phase was the analysis and redrawing of Classical Orders, which constituted over the centuries a proportional and cultural reference in architectural design. Indeed, the analysis aimed at understanding the rules, defining the parts and elements together with the dimensional 
relationships referred to a modularity, are a theoretical basis for an appropriate application of the surveying procedures. hen followed an in-depth investigation of surveying techniques: direct survey, as a core technique for the knowledge and understanding of buildings, instrumental survey with terrestrial laser scanning, which allows the acquisition of a considerable amount of metric-dimensional and morphological data to be interpreted, and multi-image photogrammetry survey, useful for smaller objects or details whose chromatic characteristics are important to capture.

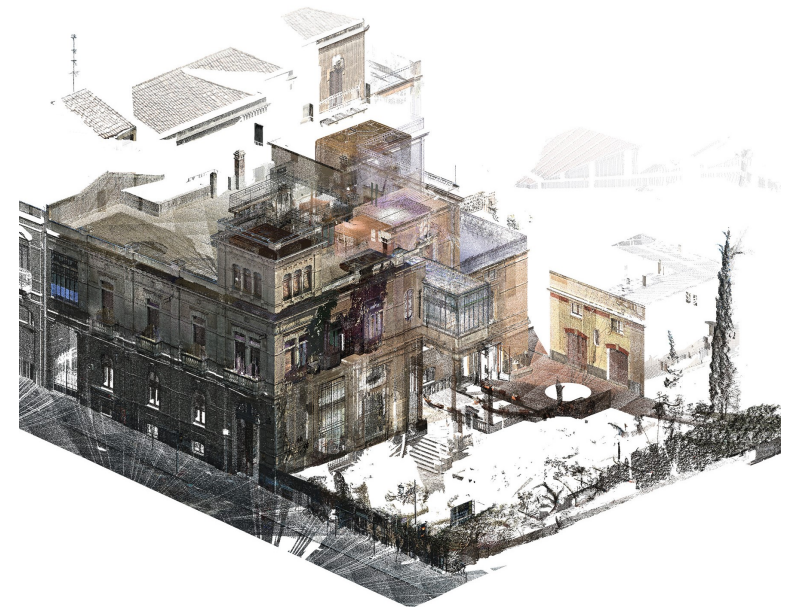

Figure 6. View of the point cloud of Villa Zingali Tetto

Once the skills training phase has been completed, nine case studies were assigned to fourteen groups of students among some of the twentieth-century-buildings designed by Carmelo Aloisi, Francesco Fichera and Paolo Lanzerotti.

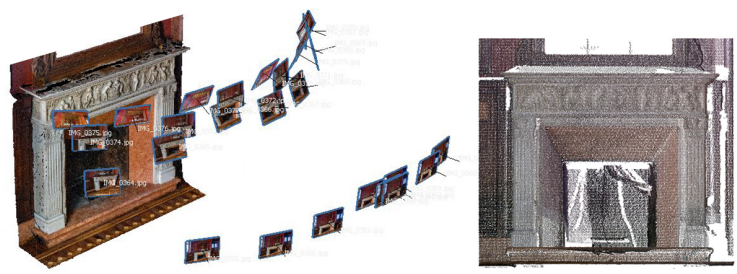

Figure 7. Villa Zingali Tetto: SfM point cloud of the fireplace

This phase of the course, held in situ in several sessions, allowed the students to deepen their knowledge of the case study assigned, first through the on-site-sketching, then by direct and instrumental surveys. The buildings chosen, public or private, different in type, have required the application of different surveying techniques, according to the circumstances.

The geometric, dimension, and morphologic features of Villa Zingali Tetto (designed by Lanzerotti in 1930) (Figg. 6 - 7) and the Cinema Odeon (designed by Aloisi in 1931) (Fig. 8) required an integrated approach using both laser scanning and digital photogrammetry, to better acquire such significant geometric-dimensional-characterized buildings with unique chromatic and material aspects in formal and decorative solutions. For the Palazzina della Società Elettrica (1913) and the Palazzo delle Poste (1919) by Fichera, laser scanning was used for restricted-to-the-public areas and façades acquisitions, while SfM was used for significant details and furniture. Only the SfM, instead, have been used for Palazzo Zuccarello (1913) and Garage Musmeci (1924) by Fichera (Fig. 9), Lazzara and Mammana houses (respectively designed by Fichera in 1919 and Aloisi in 1920) surveys of the façades, since these are private buildings, and Istituto Tecnico De Felice (designed by Fichera in 1926), for the particular spatiality of the building and the architectural and decorative apparatus.
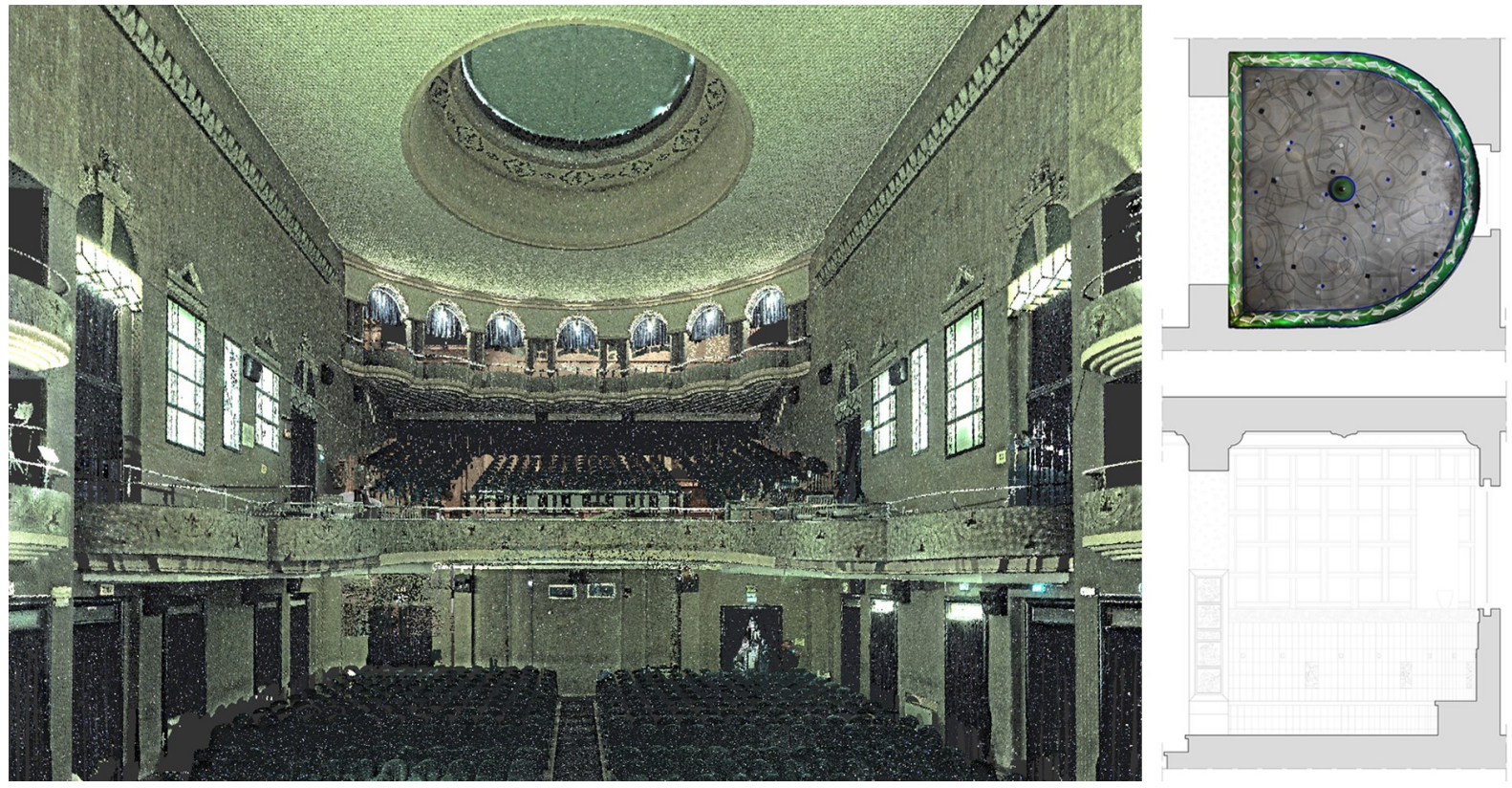

Figure 8. Cinema Odeon: (On the left) Perspective view of the TLS Point Cloud; (on the right) section and orthographic view of the lounge (restitution by Azzaro, Ciccia, Milici, Segreto, Tomasello, Zermo) 
Survey campaigns were carried out using several Laser Scanners: RTC360, BLK 360 and a Scan Station P20 by Leica Geosystem. The point cloud, suitably construed, served to obtain both three-dimensional reconstructions and revised twodimensional elaborations.
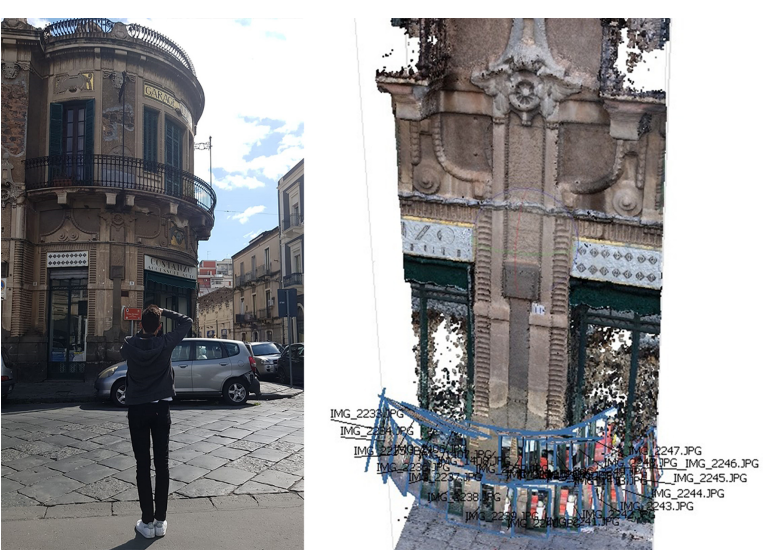

Figure 9. Garage Musumeci: (on the left) SFM survey activities; (on the right) SfM point cloud of the façade

At the end of the training experience, the engineering and architecture students participated in the organization of the event "Sharper Night 2019" at MuRa (Galizia et al., 2019). There were two main activities carried out in the context of this important event: raising awareness among visitors and a critical review of the research activities carried out. The student were involved in the decision-making process regarding the set-up of the event from the very early stages. Firstly they were asked to select the most meaningful and descriptive contents that characterize their case studies, both in terms of 2D documentation and $3 \mathrm{D}$ digital reconstructions, allowing the nonprofessional visitors for an immediate understanding of the archive projects and the restitution of the current status. This involved a review of the work carried out, concerning both the perception of the architectural object and the correctness of the graphic restitution. Therefore, the selection of the contents for the creation of the exhibition panels encouraged the active the participation of all the members of the groups that acted as curators.
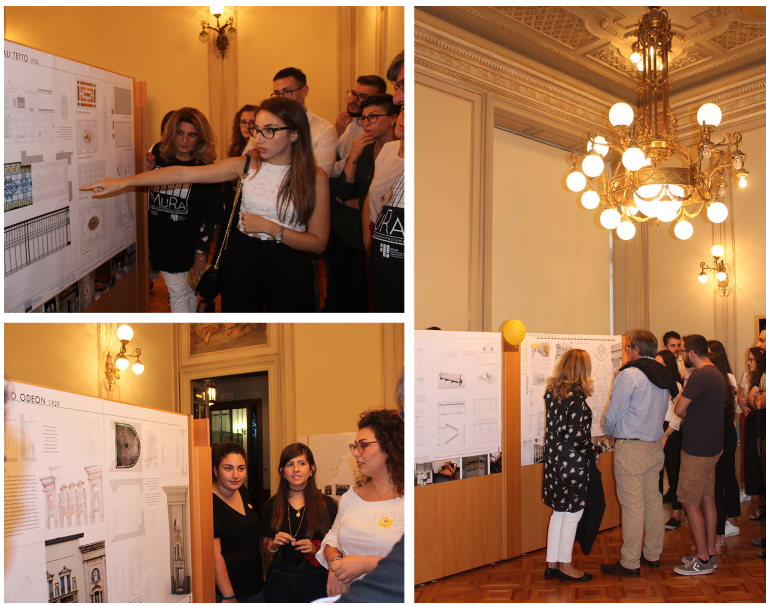

Figure 10. Some pictures of the Sharper Night event
Another aspect was the choice of the type of exhibition path. It has been decided to create an area for the projects of Fichera, whose original projects collection is kept at the MuRa, and another one for the other architects, arranged in chronological order. After the development and setting up phase, the students were asked to describe their experience and the assigned architectures to the local community, during the event. After the experience acquired during the course, they explained the archival documents research and interpretation, the reasons behind the choices for the different surveying strategies adopted and the creation of digital contents (Fig. 10). In line with Sharper Night's goals, visitors were then requested to express a preference for what they saw and to leave a comment for the work done, to get formative feedback on what was achieved, necessary as part of a review and improvement of the exhibition.

\section{CONCLUSIONS}

The outcome of the experimentation carried out at MuRa shows the value of a participatory approach in the design of new cultural experiences, fostering the development and implementation of innovative educational programmes aimed not only at university courses but also at high schools as a systematic orientation.

In fact, MuRa organizes seminars, educational courses and internal workshops open to university students, schools and the territory. This way the museum shares and disseminates knowledge and experience in the field of cultural heritage opening new frontiers in science and novel professional paths.

The use of innovative techniques and technologies in the field of heritage surveying and dissemination engages younger generations and passes down them the collective responsibility for the preservation and conservation of cultural heritage. The skills and knowledge developed, in conformity with the Faro Convention, create the basis for a Community heritage that fosters a sense of belonging to places. The museum thus becomes a socio-cultural hub, a place of exchange of knowledge and permanent, cultural and professional, formation for the territory.

Finally, the participatory approach adopted in this work creates a mutual exchange between institutions and territory. Visitors' feedbacks become guidelines for the design of new digital communication strategies that aim to improve understanding and diffusion of the museum's contents.

\section{ACKNOWLEDGEMENTS}

Cettina Santagati wrote the paragraph "Introduction" and "The mission of the Museo della Rappresentazione in Catania". Mariateresa Galizia wrote the paragraph "Methodology". Cettina Santagati and Mariateresa Galizia wrote the paragraph "Conclusion". Graziana D'Agostino wrote the paragraph "Training digital skills to young generations: criticalities and opportunities". Federico Mario La Russa wrote the paragraph "High school students training experience: from sfm techniques to the hackable museum". Raissa Garozzo wrote the paragraph "A test case for architecture-engineering students: the experience of sharper night exhibition".

\section{REFERENCES}

Bitelli, G., Rinaudo, F., Gonzales-Aguilera, D., Grussenmeyer, P., 2020. Data Acquisition and Processing in Cultural Heritage. ISPRS International Journal of Geo-Information, 1-263 
Bonacini, E., Inzerillo, L., Marcucci, M., Santagati, C., Todisco, F., 2015. 3D \#DigitalInvasions: a crowdsourcing project for mobile user generated content. Furnace Journal. 1, 1-12

CEDEFOP, Developments in vocational education and training policy in 2015-17: Italy, 2018. Link: https://www.cedefop.europa.eu/files/italy__vet_policy_developments.pdf

Gaiani, M., 2018. La rappresentazione dell'architettura: sapere e saper fare. MeTis 8(2), 13 - 49

Galizia, M., 2002: L'ambiente urbano di Catania nel '900: le architetture degli "anni '20". Gangemi, Roma.

Galizia, M., D'Agostino G., Garozzo R., La Russa F. M., Seminara G., Santagati, C., 2019. Novel cultural experiences for the communication of museum collections: the Francesco Fichera projects fund at Museo della Rappresentazione in Catania. DISEGNARECON, 12(23), 1-11

Guarrera, F., 2017. Francesco Fichera: la modernità nella tradizione dell'architettura. LetteraVentidue, Siracusa.

La Russa, F. M., 2019. H-BIM e Intelligenza Artificiale. Dal rilievo alla progettazione di un DSS per villa Zingali Tetto e le collezioni del Museo della Rappresentazione. Master's Thesis, University of Catania.

Luigini, A., Panciroli, C., 2018. Ambienti digitali per l'educazione all'arte e al patrimonio. FrancoAngeli, Milano.

Migliari, R., 2004, Disegno come modello. Riflessioni sul disegno nell'era informatica, Kappa, Roma.

Santagati, F. 2017. Il Museo della Rappresentazione dell'Università di Catania verso la riapertura. In L. Messina, Spazi espositivi della città di Catania. Patrimoni, problemi e nuove prospettive. Algra Editore, Viagrande, 95-116.

Santagati, C., Lo Turco, M., Bocconcino, M., Donato, V., Galizia, M., 2017. 3D models for all: low-cost acquisition through mobile devices in comparison with image based techniques. potentialities and weaknesses in cultural heritage domain. ISPRS - International Archives of the Photogrammetry, Remote Sensing and Spatial Information Sciences. XLII-2/W8. 221-228.

DOI: 10.5194/isprs-archives-XLII-2-W8-221-2017

Santagati, C., Galizia, M., Basso A., La Russa, F. M, 2018. Reshaping the Identity of University Museums: The Museo della Rappresentazione in Catania as Digital Innovation Hub for the Engagement of New Generations and the Development of the Territory. Earth 2018, AISC 919 - Proceedings of the 1st International and Interdisciplinary Conference on Digital Environments for Education, Arts and Heritage. 737 - 746.

DOI: 10.1007/978-3-030-12240-9_75

Santana Quintero, M., Georgopoulos, A., Stylianidis, E., Lerma, J.L., Remondino, F., 2017. CIPA's Mission: Digitally Documenting Cultural Heritage. APT Bull. J. Preserv. Technol., $48,51-54$.

http://umac.icom.museum/about-umac/what-is-umac/2017/ last accessed 4 May 2020 